\title{
Using Printed Palm Leaflets in Modern Crafts according the International Fashion Trends
}

\author{
Heba Mohamed Okasha Abu Elkamal Mohamed Elsayegh \\ Faculty of Applied Arts, Benha University, Egypt \\ heba.okasha2008@gmail.com, heba.okasha@fapa.bu.edu.eg
}

Keywords: printed leaflets, modern crafts, fashion trends, dyed palm leaflets, textile dyes, textile printing

\begin{abstract}
Egypt is one of the most important and oldest countries in the world that is known for producing dates, because date palms are available in all the cultivated areas of the country. Taking in account the date palm by-products (such as palm leaflets), this paper focuses and outlines the utilization of palm leaflets in making modern crafts and accessories in a creative way ("out of box") and at the same time following the international fashion trends. This utilization can result in benefits like achieving added economic value in two ways: creating trendy modern fashionable crafts and achieving the concept of "zero waste". Palm leaflets can be mixed and matched with fabrics and leather waste according the design idea. By using techniques of textile printing and dyeing to create more attractive designs according the trend, which can be employed in the palm leaflets and fabrics, a variety of innovated designs are created and can be applied in modern crafts according the international fashion trends for making accessories according the season. Also, dyed palm leaflets are mixed and matched with printed fabrics and leather wastes generating very unique up-cycled products in modern crafts and fashion accessories. At the end, a boxy bag prototype is implemented according the proposed outlines as a final product made from woven leaflets mixed with waste of fabrics and leather up-cycling. The main purpose of this paper is to highlight making fashionable accessories products according to the international fashion trends using mixed media as up-cycling product from (printed \& dyed palm leaflets according the color of the season), waste of fabrics and waste of leather.
\end{abstract}

\section{Introduction}

Cultivation of date palms (Phoenix dactylifera) in Egypt goes back to thousands of years. Agricultural operations on date palm, like pollination, are known at least since 2,500 BC. In Egypt, date palm is cultivated and grown everywhere. Date palm grows in warm weather countries and has a tall trunk with a mass of long pointed leaves at the top [1]. Egyptian people use the parts of date palms in many things, like using palm leaflets in plaited cradle [2]. Nowadays date palm plantations are spread out all over country; wherever water is available. Egypt has more than 15 million date palm trees and is considered the world biggest producer of dates. It has a long heritage of utilization of date palm by product since ancient times [3]. The palm leaflets have been collected from the palm trees and dried by a traditional way, then woven as palm leaves folding (Fig. 1), so after that they can be used in many things, such as creating and making new ideas in modern crafts (such as, bags and accessories), furniture, tables sets and many other creative productions. These creative industries may be made by traditional or modern way with a unique and different concept according the international fashion trends for making accessories according the season. 

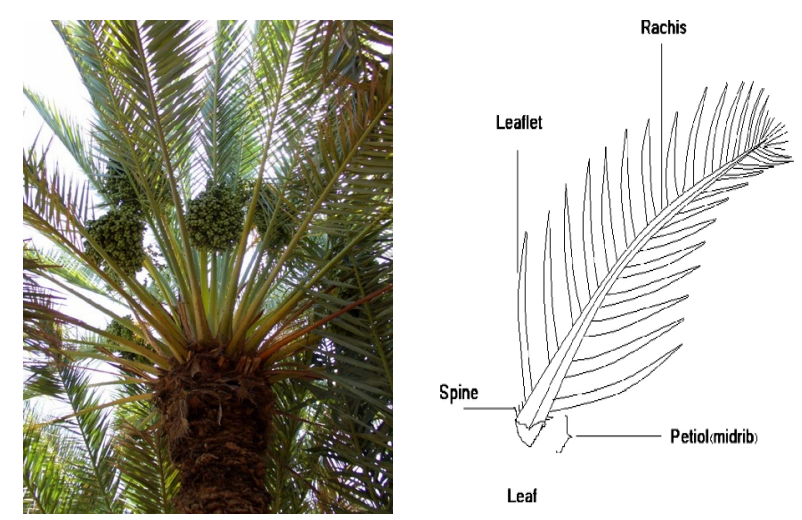

Fig.1: Egyptian date palm tree - parts of the leaf- ways of weaving leaflets [4][5].

\section{Purpose of the research}

- Making unique modern crafts (bags and accessories) from printed and dyeing date palm leaflets according to the international fashion trends for the season spring/summer (S/S) 2018, So printing and dyeing the palm leaflets is just for making catchy fashionable colors .

- Applying textile printing, dying methods and techniques as only helping method in coloring and decorating the date palm leaflets, which could be mixed with fabrics and leather waste, for creating modern crafts (bags and accessories) by implementing the concepts of "Zero Waste" and "up-cycling" using these materials.

- The research deals with only the innovation and creativity in using different materials in designing bags according the season trends focusing mainly on Palm leaflets.

\section{Methods and ( Methodology ) of the research}

The research used a mixture of experimental and analytical methods:

\section{Experimental methods}

- The researcher used experimental method by implementing textile dyeing and printing (methods and techniques) in many kinds of palm leaflets weaving according to the design of the type of bag or accessory, and the purpose of this step is to produce many colors of palm leaflets that meet the international fashion trends of the season.

- The researcher made some suggested sketches ideas for bags according to the international fashion trends S/S 2018.

- The researcher implemented one only prototype from the ideas, using printed palm leaflets, waste of fabrics and leather to make an "up-cycled" product according the international fashion trends in bags and accessories .

\section{Analytical method}

- The researcher used the analytical method in studying the results of using traditional manual dyeing and printing methods in coloring palm leaflets to meet the colors of the season (international season colors S/S 2018).

- The researcher chose the best result and the most suitable printed palm leaflets for the accessory piece (Suggested implemented bag) in both sides (design, color trends and performance requirements). 


\section{Literature review}

\section{The international fashion trends in bags and accessories}

The international fashion trends are very relevant for fashion industry. International fashion trends mean what is hip or popular at a certain point in time. While a trend usually refers to a certain style in fashion or entertainment [6]. The international fashion trends lead the market to meet the client requirements and needs. Bags and accessories are very important elements for fashion industry. Palm bags are an important essential for Summer Fashion Trends 2018 according to many of the international fashion trends reports and many other sources in the fashion industry. Many brands have shown their new collections summer 2018 and lay emphasis on the bags and accessories made from hand-woven palm as environmentally friendly products. This can diminish the wastes derivate from palm trees and also follow the international fashion trends, sustainability and environment requirements (Fig. 2). According to 20 fashion trends for spring/summer 2018, the usage of palm leaf in handcrafts and manufacturing is essential in this season. Also, according fashion trends 2019, palm leaf is also an important and essential fashion trend and very good inspiration source for textile printing, which can be used in bags and accessories beside other trends like tie-dye [7-13] (Fig. 3).

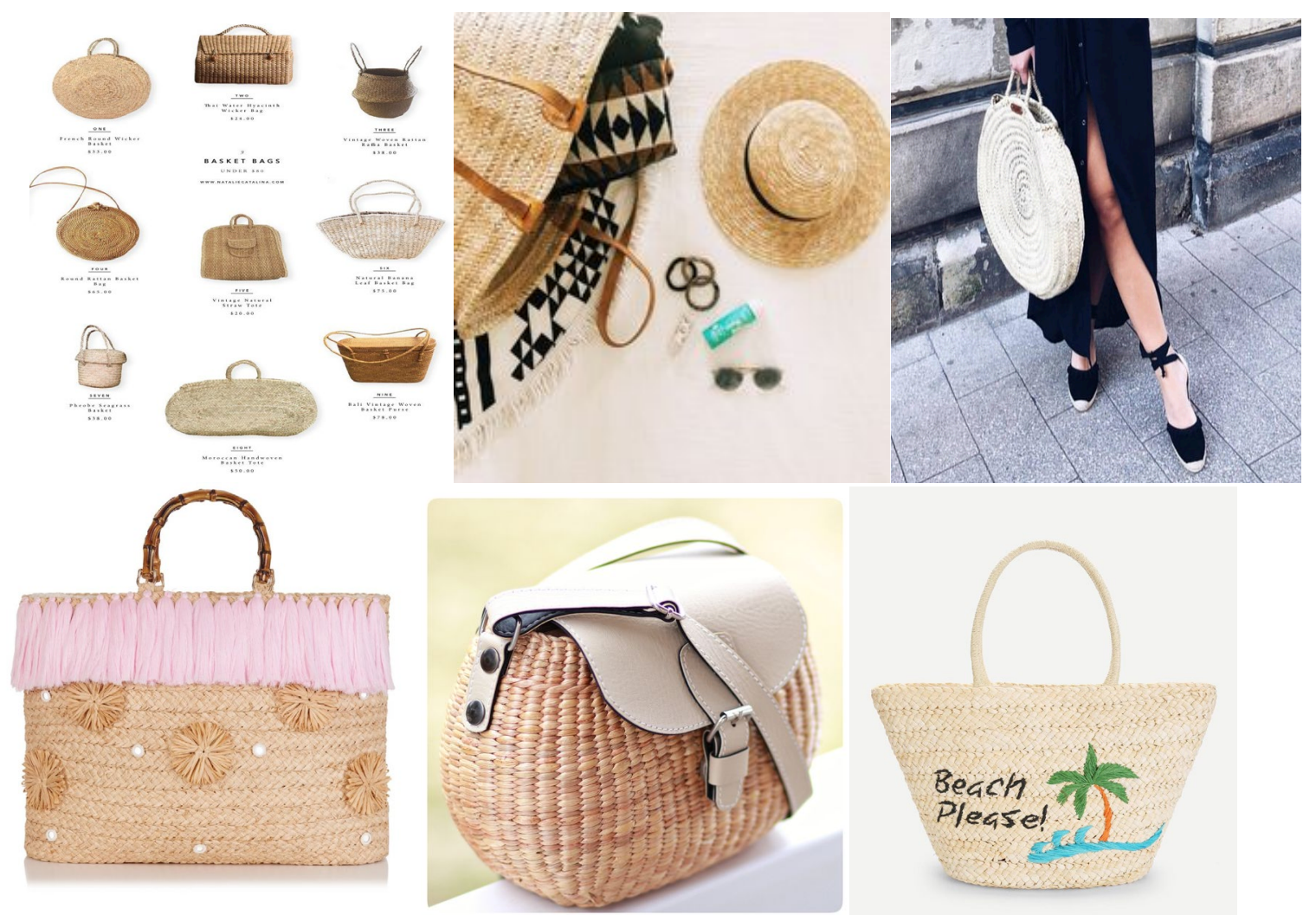

Fig. 2: Bags and accessories made from palm leaflets according the international fashion trends (international brands S/S 2018) [8] [12] [15]. 


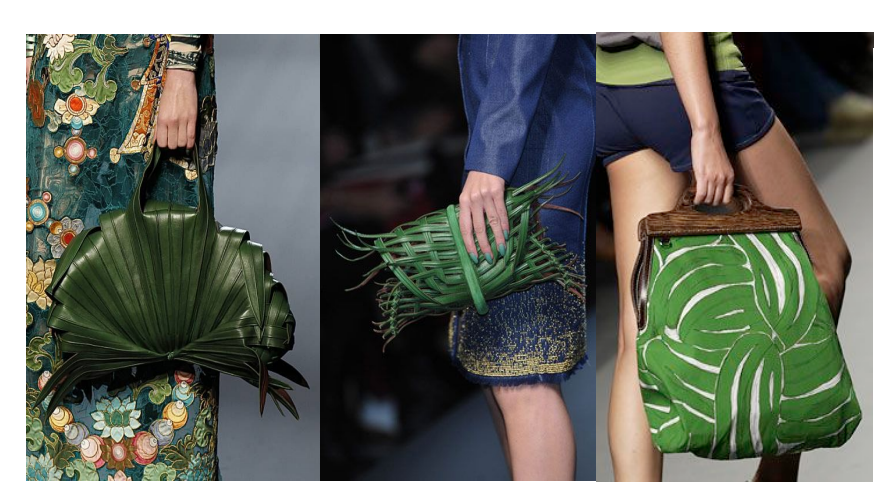
doi: https://doi.org/10.21741/9781644900178-29

Fig. 3: Bags and accessories made from palm leaflets as an important source of inspiration for modern handcrafts and accessories designers through many seasons [13].

\section{The international fashion trends in bags materials as modern crafts}

The international fashion trends in bags and accessories deal with everything related with colors, silhouettes and collection materials, which were presented at some important trade fairs in Milano (Italy), offering a preview of what designers have got as inspirations for their spring/summer 2018 footwear and leather accessory designs. And there was plenty of inspiration to be found. Leather was still the main attraction with a multitude of new patterns and finishes. But the rise of non-leathers could not be ignored. New meshes and neoprene versions catapulted materials into the future, whereas natural straws, raffia and hemp promoted eco-friendliness and sustainability [14] [15].

So, using natural materials like palm leaflets is so trendy in fashion industry and can add value to the product by implementing the concepts of sustainability and eco-friendliness. The international fashion trends and the big brands realized very well the raise of consumer awareness of these concepts and how implementing them, can help increase consumer loyalty to the brand, especially sustainability and eco-friendliness, which become a worldwide demand and necessity.

\section{Experimental methods}

\section{Using textile dyestuff in dyeing palm}

The researcher implemented some methods and techniques of textile dyeing and printing in coloring the weaving palm leaflets, to make different colors and effects on them. These obtained colors and designs differ from each other according to the idea and the implementation of the designs. Also, the researcher made these designs according the international fashion trends in patterns and colors of bags and accessories.

The researcher used reactive dyes in coloring raw palm leaflets, fiber reactive (Procion type Dyes). The dye is powder; the employment of dyes as follows:

The reactive dyes were in powder form and then dissolved in water. The liquor ratio was $15 \mathrm{~g}$ dyestuff reactive dye: 1 liter of water.

Step 1: As known for reactive dyes, it should be started in a neutral medium when the dye does not react either with the fiber or with the water to prepare the dyestuff solution.

Step 2: After washing the woven palm leaflets with warm water (Fig. 4), they were immersed into the dyestuff bath for (25-30) min.

Step 3: Common salt $(\mathrm{NaCl})$ was added to the reactive dyes, dissolving it in the bath, and then the woven palm leaflets were left in the bath extra (25-30) min.

Step 4: Finally, the fixation of the dye was done by alkali addition (sodium carbonate or soda ash $-\mathrm{Na}_{2} \mathrm{CO}_{3}$ ). As the dye is already exhausted into the palm leaflets, it is not be available for 
reacting with water. As known the hydrolyzed dye, due to affinity forces, is absorbed by the palm and retained in it [16] [17].

Result: by Implementing this way of dyeing, we can get light coloring and many color tones depending on the following factors:

- The kind of weaving palm leaflets (like warp and weft weaving and according this weaving is narrow or wide or open little bit, so we can obtain more results of light tones and shading ), this is can be changeable according the required designs of accessories and bags .

- The rate of dye exhaustion into the palm, by using fiber reactive (Procion type Dyes) because this kind of dye can be very effective in dyeing. This way achieves very nice tones of colors (Fig. 5).

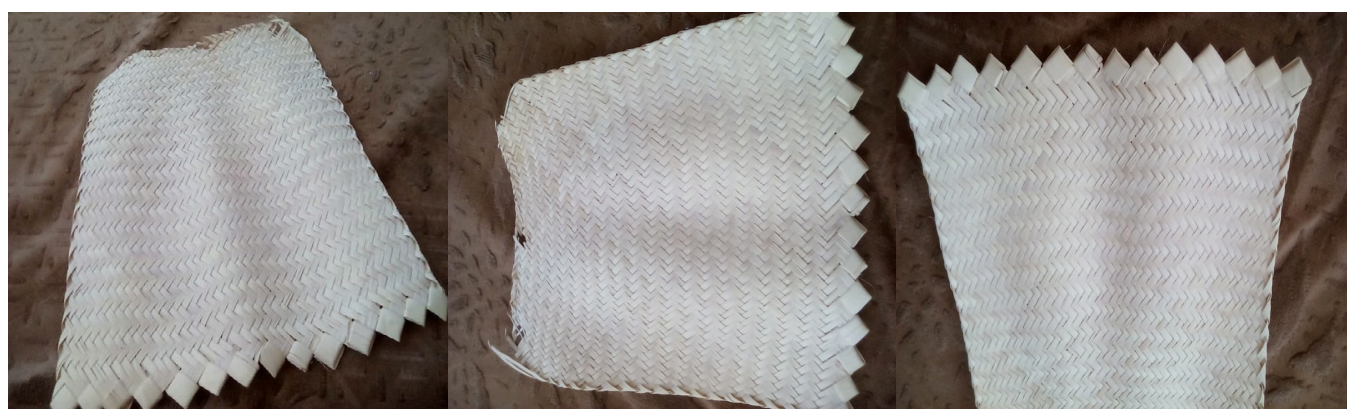

Fig. 4: Egyptian data palm leaflets - Raw Woven leaflets- before dyeing and printing.

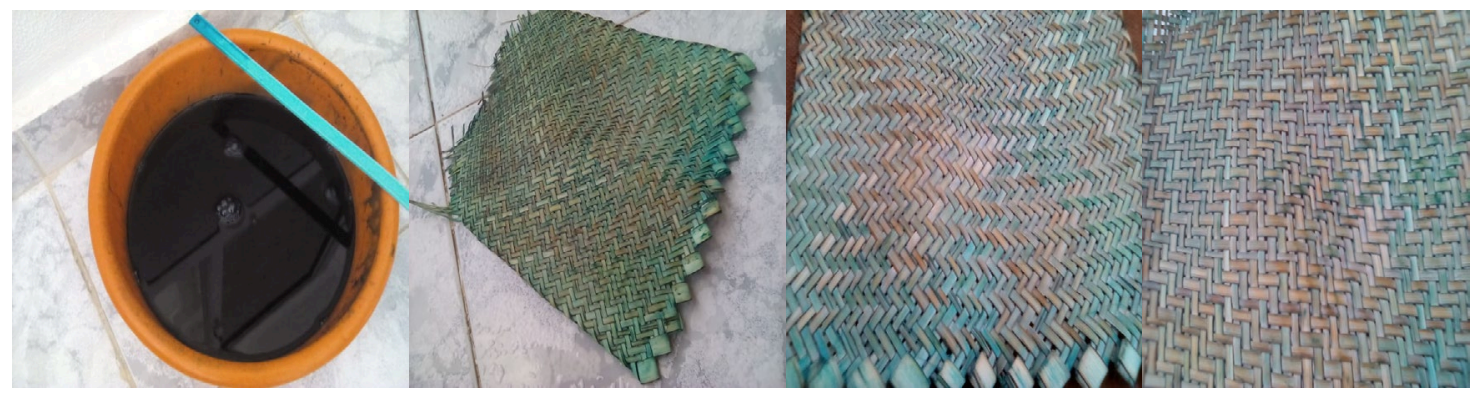

Fig. 5: Steps of dyeing and printing the Raw Woven leaflets - after dyeing and printing in the dye bath in home

The researcher didn't use the natural dyes instead of reactive dyes as synthetic dyes because of the following reasons:

- $\quad$ It is more expensive than the reactive dyes as synthetic dyes.

- Although natural dye sources are renewable, but sustainability can be big issue for natural dyes because producing them require vast areas of land and this is can't be achieved easily

- The availability of raw materials of the natural dyes can vary from season to season, place, and species, whereas reactive dyes as synthetic dyes can be produced in all year round.

- $\quad$ Sometimes Color pay-off from natural dyes and going to fade quickly.

\section{Using textile printing methods and techniques in coloring palm leaflets}

There are a lot of textile printing methods and techniques that can be used it in coloring and decorating palm leaflets like: stencil, direct painting and drawing, silk screen and block printing with some motifs and patterns. In this research, direct drawing and stencil were used to make a sample (prototype). Also, in this field of fashion industry, a lot of previous printing methods and techniques can be used to create and implement many designs of bags and accessories according 
the international fashion trends (color theme, materials and silhouettes, etc.). The implementation of these techniques was as follows:

- Direct painting and drawing: we can draw and indicate the outline of the motifs and patterns that we want to apply in the weaving palm leaflets. Then colors of parts or textures are according the design coloring theme and plan (Fig. 6 and Fig. 7).

- Stencil: stenciling produces an image or pattern by applying pigment to a surface over an intermediate object with designed gaps in it, in which is created the pattern or image, only allowing the pigment to reach some parts of the surface. The stencil is both the resulting image or pattern and the intermediate object [18]. Stencil can be applied at any surface, not only in the palm leaflets, like wood, furniture, wall, garment and textile, etc. It is a very effective way to make fast and unique results in decorating and coloring surfaces (Fig 8).

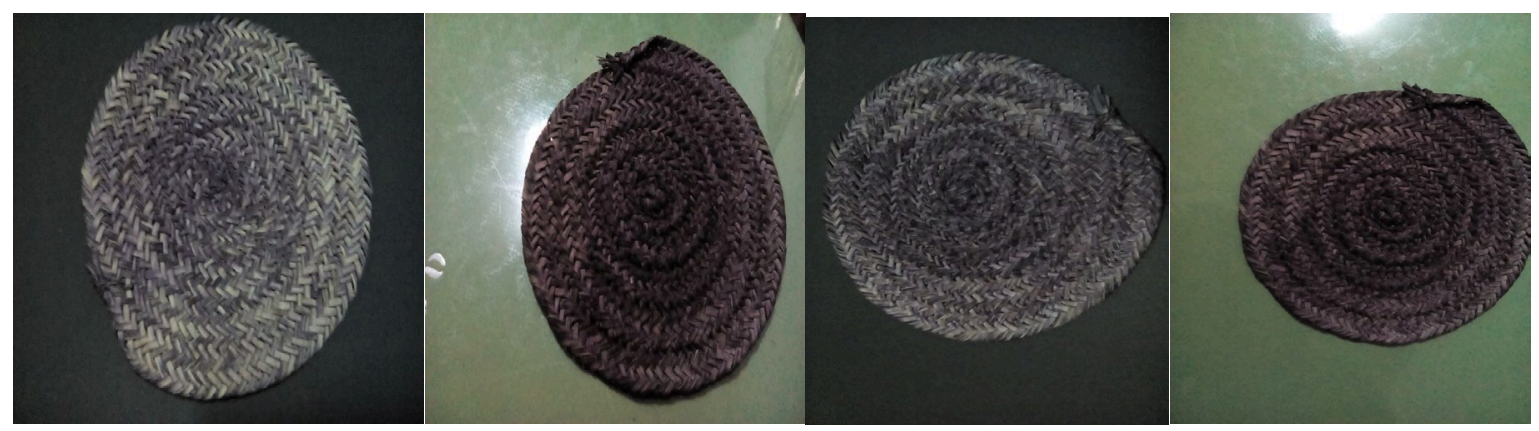

Fig. 6: Experimental results of dyeing and printing - the raw woven leaflets- after dyeing and printing (direct painting).

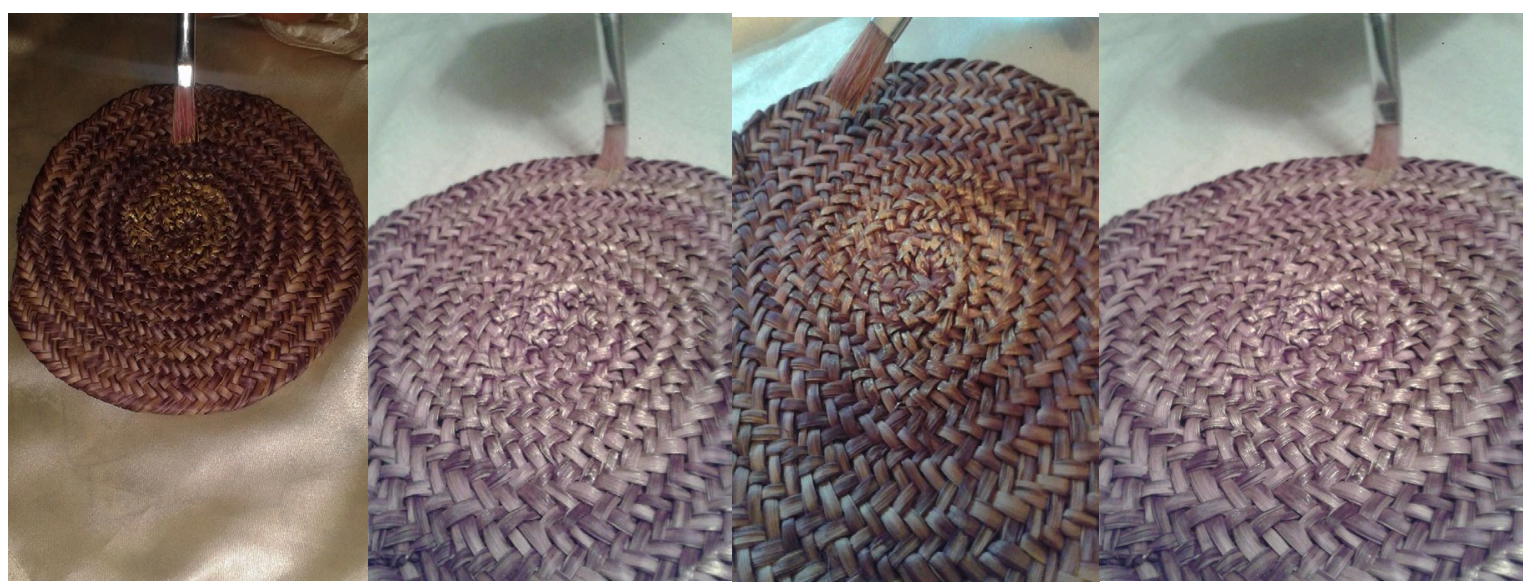

Fig. 7: Experimental results of dyeing and printing the raw woven leaflets- after dyeing and printing (direct painting). 


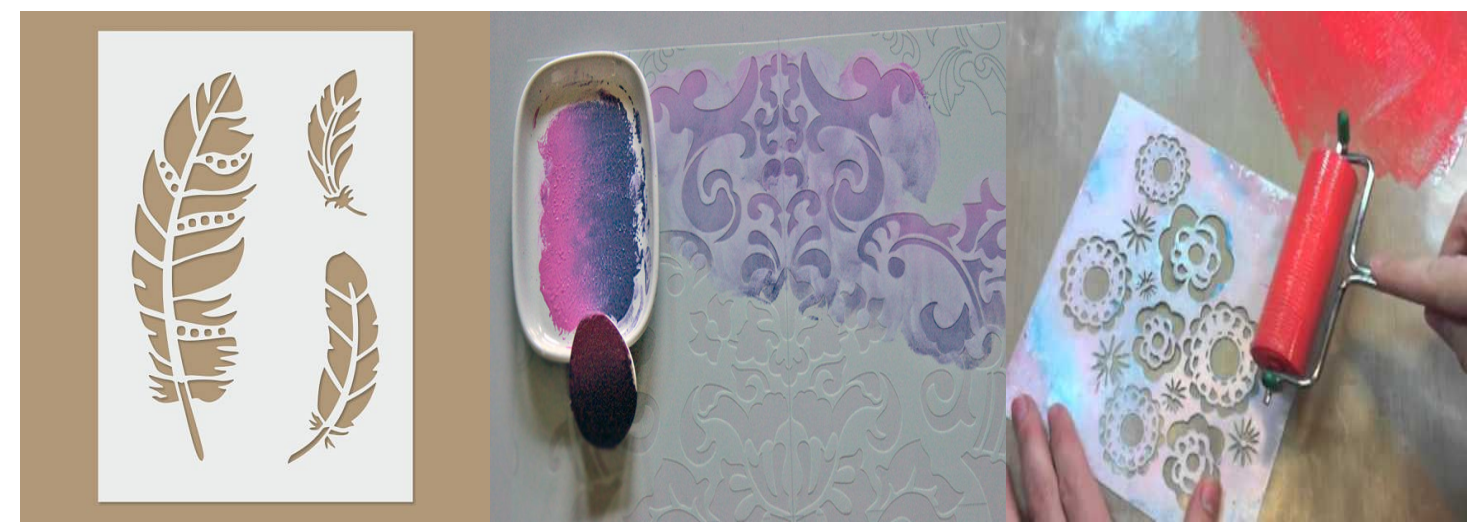

Fig. 8: Stencil technique and the implementation of the pigment and how it can be applied in many surfaces to create unique designs [18].

\section{Up-cycling trend worldwide:}

Up-cycling is known also as creative reuse. Up-cycling is defined as the process of transforming by-products, waste materials, useless, or unwanted products into new materials or products of better quality or for better environmental value, and the opposite of the up-cycling is down cycling [19]. Up-cycling nowadays is a growing trend in every industry and since the necessity to make creative reuse become urgent for unwanted products or waste materials. Up-cycling is an innovated method of recycling waste into products of higher quality. So, up-cycling is a design solution to an environmental problem.

Topics to up-cycle design are indicated as following [20]:

- Always know what is on offer before you start designing.

- Follow your own waste stream.

- No scrap is too small.

- Ugly can be beautiful too.

- Finishing is the key to good design.

\section{Up-cycling ideas in the research:}

This research suggested and created new ideas of modern crafts, like bags designs which are made from printed and dyed woven palm leaflets as basic and main material in implementation the design, because Egypt is the first country in producing the data palm worldwide, and this has been achieved according to the previous topic ("always know what is on offer before you start design”), using these palm leaflets in achieving sustainability of the products, as palm leaflets is available raw materials and also coloring this palm leaflets by dying and printing create more added value to the palm leaflets to use in more fashionable crafts and products like fashion accessories ( Bags - belts ..............) .

-Also, according to "follow your own waste stream using waste of materials", the researcher used waste of fabrics and leather to reuse and up-cycling in order to create new and innovated products.

In fact, "no scrap is too small", because very small waste of fabrics and leather were employed to make the first prototype (sample).

- By mixing and matching colors and waste of materials in one design, so you can create beauty and innovation from ugly ("ugly can be beautiful and fashionable too").

- According to "finishing is the key to good design", the sample of the bag (first prototype) was made with high finishing quality and accurate details. 


\section{Results and discussions}

\section{Making the first sample (prototype):}

After all the previous experiments in coloring and printing the palm leaflets, the researcher will turn to the main core of the paper which is using this dyed and printed palm leaflets in making modern crafts according the international fashion trends. The idea of the first sample (prototype) depended on using the previous result of printed palm leaflets (Fig. 5) and then mixing and matching them with other materials to make and implement the idea, as follows:

- $\quad$ The researcher also dyed the waste of the Egyptian heavy fabrics with green colors by using also the reactive dyes, to match with the printed palm leaflets color as one of the color trend of the year S/S 2018. The heavy Egyptian fabrics have been dyed using tie-dye technique to make texture on fabrics matching with printed woven palm leaflets.

- Mixing and matching with the three materials: printed palm leaflets, dyed waste fabrics and the waste of leather (Fig. 8).

- Making fast design sketches of bags to choose the most suitable design to be implemented by using the three materials (up-cycling), and also following the international fashion trends summer 2018 (Fig. 9).

- Choosing the most suitable design to be implemented by using the three materials (Fig. 10).

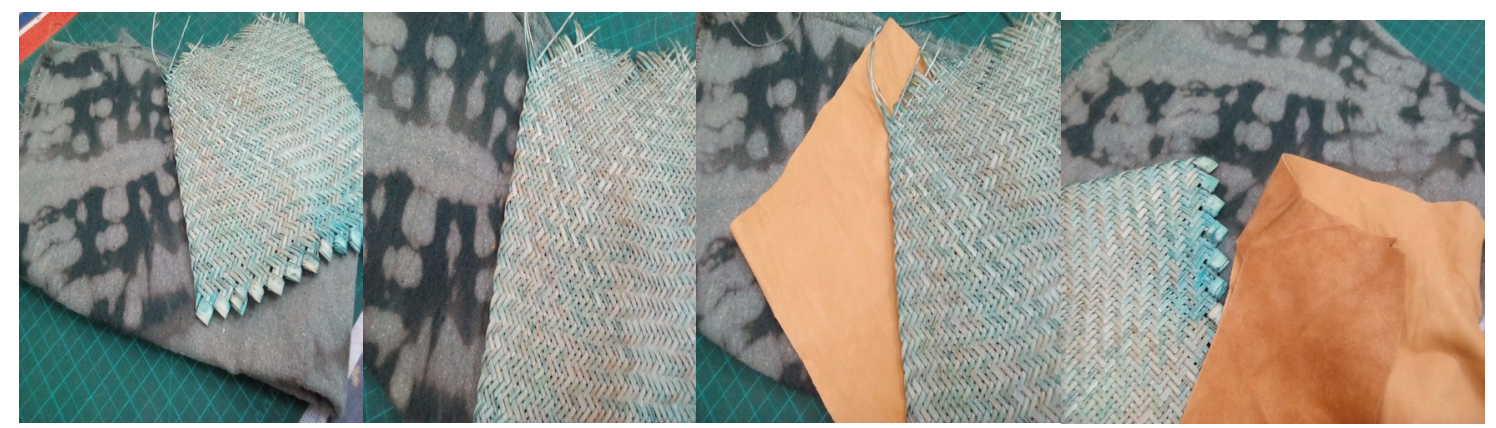

Fig. 8: Steps of making (mix and match) dyed woven leaflets with waste of fabrics and leather up-cycling
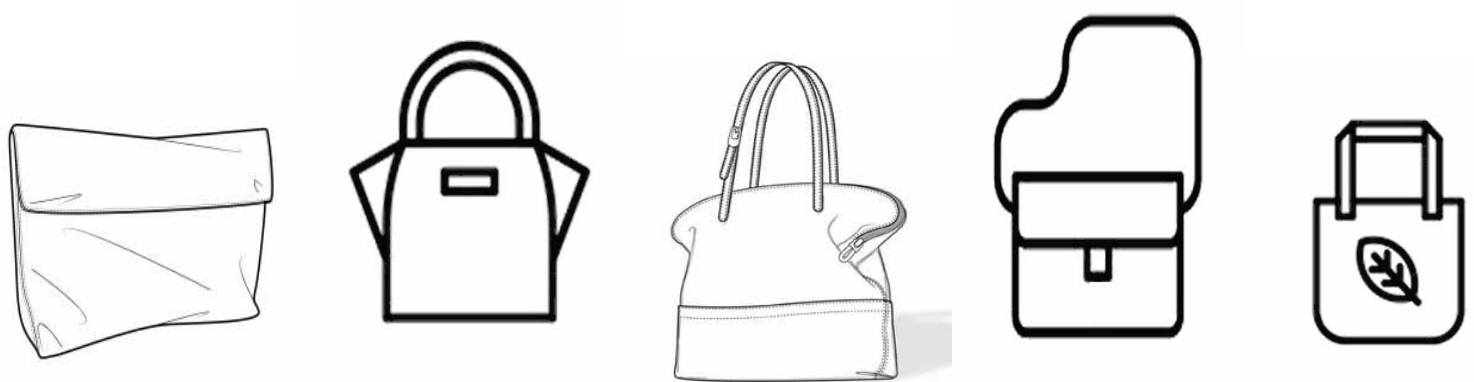

Fig. 9: Some suggested sketches of bags suitable to be implemented from printed palm leaflets and (waste of fabrics and leather) up-cycling according the international fashion trends S/S 2018. 


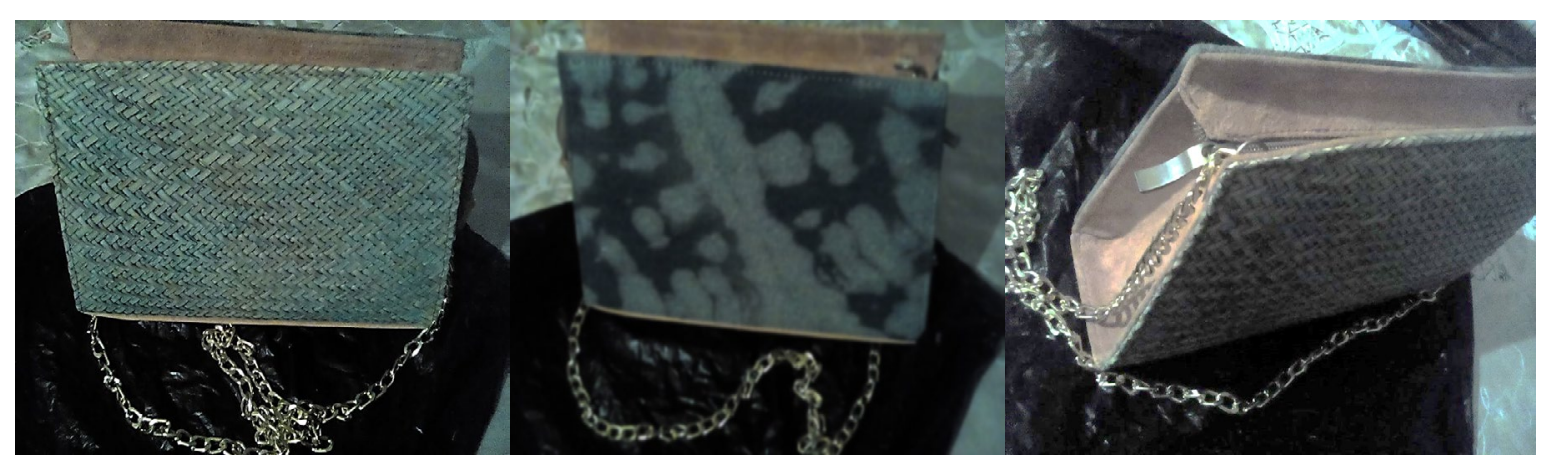

Fig. 10: Sample of the implemented bag (prototype) as a final product which was made from woven leaflets mixed with waste of fabrics and leather up-cycling

Product (Prototype) Specifications

\begin{tabular}{l|l}
\hline Product name & Up-cycling bag as shown in Fig.10 \\
\hline $\begin{array}{l}\text { Materials \& } \\
\text { techniques }\end{array}$ & $\begin{array}{l}\text { Printing palm leaflets (side), waste of fabrics dyed with (tie-dye) method } \\
\text { using the same procedure of palm leaflets dyeing in another side). } \\
\text { Using waste of leather in the (two sides), as shown in Fig.10 }\end{array}$ \\
\hline Size & $20 \mathrm{~cm}(\mathrm{~L}) * 17 \mathrm{~cm}(\mathrm{H}) * 5 \mathrm{~cm}(\mathrm{~W})$ dimensions of the bag \\
\hline Description & $\begin{array}{l}\text { The idea of making this boxy bag depended on palm leaflets as essential } \\
\text { and main material and this palm is dyed or printed, waste of dyed heavy } \\
\text { fabrics and leather and the inner fabrics is natural cotton. }\end{array}$ \\
\hline $\begin{array}{l}\text { Edge material } \\
\text { and color }\end{array}$ & Waste of mustard leather in two sides \\
\hline Target client & $\begin{array}{l}\text { The targeted client age is (20-45) years, loves eco-friendless and } \\
\text { sustainability, craze for changing bags, fashion materials and afternoon } \\
\text { boxy bag. }\end{array}$ \\
\hline
\end{tabular}

Different between this study and the previous attempts in this field (brief critical view):

This study focuses on making fashionable handicrafts from dyed and printed palm leaflets, according the international fashion trends S/S 2018, also using this dyed palm leaflets in designing and making up-cycling crafts like the prototype (bag) which has been implemented by using the printed and dyed palm leaflets and waste of (leather and dyed fabrics) and up-cycling also is very trendy worldwide.

Meanwhile, the previous studies in this field related and focused more in the technical side of using dyes in palm leaflets, yarns and fabrics. Also measuring and enhancing color fastness for all of them.

Otherwise there are some previous studies that deal with coloring and dyeing the palm leaflets without focusing and taking attention to the international fashion trends of the season (colors, designs and shapes of bags.......)

\section{References}

[1] Information on: https://dictionary.cambridge.org/dictionary/english/palm.

[2] Loutfy I. El-Juhany- Degradation of Date Palm Trees and Date Production in Arab Countries: Causes and Potential Rehabilitation-Prince Sultan Research Centre for Environment, Water and Desert, King Saud University Australian Journal of Basic and Applied Sciences, ISSN 19918178 (c) 2010, INSInet Publication 4-8 (2010) 3998-4010. 
[3] Information on: https://www.bypalma.com/.

[4] Information on: https://www.pinterest.com/pin/308778118171108000/?lp=true.

[5] Information on: http://b-c-ing-u.com/2017/07/25/secrets-sahara-dates-part-2-date-palmfronds-industry/fig-1-structural-parts-of-date-palm-tree/.

[6] Information on: https://www.vocabulary.com/dictionary/trend.

[7] Information on: https://www.elitedaily.com/p/the-summer-2018-beach-bag-trend-you-needright-now-8945190.

[8] Information on:

https://i.pinimg.com/originals/29/4f/a2/294fa2a82e349e4cbd7c5a1935f56827.jpg.

[9] Information on:

https://i.pinimg.com/originals/34/3b/a6/343ba6fafe6ddf992cf9e3d60486eda1.jpg.

[10] Information on:

https://www.marieclaire.co.uk/fashion/summer-fashion-trends-2018-553795.

[11] Information on:

https://www.marieclaire.co.uk/fashion/summer-fashion-trends-2018-553795.

[12] Information on:

https://www.pinterest.com/pin/AQbA3m2uwy6ogS2Y868ztHmCGyV9yFztjSqUzY9eBqH7LVc YYvU-pTs/.

[13] Information on:

https://i.pinimg.com/originals/34/3b/a6/343ba6fafe6ddf992cf9e3d60486eda1.jpg

[14] Information on: https://www.colourandtrends.com/.

[15] Information on:

https://www.colourandtrends.com/blog/2017/3/15/lineapelle-is-enthusiastic-aboutspringsummer-2018.

[16] Information on:

https://www.researchgate.net/publication/268881605_The_chemistry_of_reactive_dyes_and_thei r_application_processes.

[17] Information on:

http://textilelearner.blogspot.com/2012/01/dyeing-of-cotton-fabric-with-reactive.html.

[18] Information on: https://en.wikipedia.org/wiki/Stencil.

[19] Information on: https://en.wikipedia.org/wiki/Upcycling.

[20] Information on: www.ecochicdesignaward.com. pdf. 